\title{
SYMPTOMATIC SPEECH DISORDERS - THEORETICAL BASIS AND PRACTICAL APPLICATIONS
}

\author{
Adela Hanakova \\ Katerina Stejskalova \\ Palacky University in Olomouc, Czech Republic
}

\begin{abstract}
Area of symptomatic speech disorders in person with sensory disabilities still stands on the edge of the interests of professionals. The article deals with the issue of speech therapy, special education of person with hearing impairment, and special education of person with visual impairment. Disruption of communication for people with sensory disabilities is one of the determinants of the quality of life. Within a broader theoretical framework symptomatic speech disorders in person with visual and hearing disability will be planted partial results of research with qualitative orientation. The exhibition will include in particular the issue of awareness, experience, access and awareness of speech therapists in the intentions of the issue.
\end{abstract}

Keywords: symptomatic speech disorders; sensory impairment; communication disorder; speech therapists.

\section{Introduction}

From an infant's birth, parents and the infant begin an exchange of communication that lays the groundwork for their relationship. As children become older, they learn to understand more of what their parents are communicating and find ways to communicate consistently their need and want to their parents. Long before formal language emerges, children and parents are communicating through preverbal methods. The presence of a visual or hearing impairment intermits conventional preverbal communication and differences develop in the ways children communicate and the topics about which they communicate (Sapp, 2001). Nowadays for hearing and visual impaired children there are many opportunities that provide enhanced ways hearing and visual stimulation.

In the context of increasing incidence of multiple disabilities and also increasing demands on professionals who provide intervention, we focused on the current relatively marginalized issue - symptomatic speech disorders in people with sensory impairment. Our main goal was the exploration of current needs of special education practice.

The intention of presented research was exploration of the current state from the perspective of speech therapists and identification of specific and potentially problematic aspects. Due to this plan was designed mixed design research, this paper is focused on qualitative part of the research. Qualitative 
data, obtained through semi-structured interview method, serve us as primary probe; strive for a deeper insight into the current state.

\section{Children with hearing impairment}

Authors (e.g. Estabrooks, 2006; Landolfi et al., 2011) believes, that the main tasks of the speech therapy in children with hearing loss are acoustic, visual and stereognostic attention, hearing perception, communication as principal requirement for verbal language in all its aspects (phono-articulation, lexicon, morphosyntax) and cognitive skills as well; it is always necessary referring to the mainstream development scales and considering the gap between impaired children and normal hearing peers. „Communication, cognition, language, and speech are interrelated and develop together. It should come as no surprise to us that the key to intervention with deaf children is to establish, as early as possible, a functional communication system for the child and the parents. Early intervention programs need to be multidisciplinary, technologically sound and most important; it should take cognizance of the specific context (community, country) in which the child and family function" (Daneshmandan et al. 2009, p. 363). The study of building the alphabetic principle (Bergeron et al., 2009) suggests that children who are deaf or hard of hearing, even those who have delays in language, are able to learn the foundation for the alphabetic principle during pre-kindergarten. Although the long-term consequences of early instruction on the alphabetic principle need to be explored, such a finding holds promise for improving literacy skills of children who are deaf or hard of hearing.

The field of hearing impairment has more correlations toward speech therapy and is typically in sphere of interest of experts in this area. It is the most debated topic in the area of symptomatic speech disorders, and also most well known among the speech therapists.

\section{Children with visual impairment}

In children with congenital blindness or profound visual impairment, several studies have found a developmental delay in first-order false belief performance compared to typically developing children (Pijnacker et al., 2012).

Researchers (Rowland, 1984; Sapp, 2001) have specifically investigated the development of preverbal communication in children with visual impairments. They found several similarities between preverbal communication in children with visual impairments and those with typical sight. Children with visual impairments produce typical quantities of vocalizations and engage in the same communicative functions and similar communicative routines (Chen, 1996). Additionally, if children have low vision, they use shared gaze and pointing as means of preverbal communication (Preisler, 1991). The findings of Pijnacker et al. showed: „when using appropriate, verbal tasks, children with a 
variety of congenital visual impairments had no developmental delay in more advanced theory of mind understanding. Despite a limited access to visual information during interactions (e.g. joint attention, mutual gaze, facial expressions, and gestures), children with congenital visual impairment can develop an effective theory of mind" (2012, p. 2446).Currently, very little is known about the ability of people who are blind to interpret speech accompanied by nonverbal information. The findings lend support for the premise that people with visual impairments are able to make correct assumptions about intentions, feelings, and attitudes of other people on the basis of available information during communication. The results also suggest that the lack of direct access to gestures and facial expressions during communication does not tend to impair the understanding of utterances by people who are blind (Sak-Wernicka, 2014).

Study of Dickinson \& Taylor (2011) shows that if hearing is compromised, then an observer's speech-reading ability is sensitive to changes in vision. It is likely that visual loss will have consequences for speech-reading ability. This will be particularly relevant to the elderly population who are often found to have a dual sensory loss that causes compromise to both visual and auditory sensory reception. Some of the difficulties in communication reported by the elderly with reduced hearing could be visual as opposed to auditory in origin. Research of Bruce (2002) shows, those children who are visually impaired and have additional disabilities may experience the greatest risk factors for developing ineffective communication skills.

\section{Methodological aspects}

Design of research combines quantitative and qualitative dimension. In this paper we focus only on the qualitative aspects of symptomatic speech disorders in people with sensory disabilities. The intention was exploration of the current state from the perspective of speech therapists and identification of specific and potentially problematic aspects. Due to this plan was designed mixed design research. Qualitative data serve us as primary probe; strive for a deeper insight into the current state. In this context, do not seek to generalize the results to the entire population of the speech therapists, but rather a description of the specific aspects and open space for applied research. Qualitative research usually emphasizes that the results have to be read locally in a certain context. We leave it to the reader to be learned from the results, to made subjective conclusions and reflect it further in theory and practice.

\section{Data management, analysis and interpretation of data}

Further to the principle of hermeneutical spiral took place a process of data management (i.e. the process of interaction between data acquisition, data reduction, data capturing and extrapolation of conclusions) cyclically. In this 
concept, the implementation of research closely linked with data management and process of analysis and interpretation of findings.

An integral part of data management is the phase of systematization of data. Based on the expertise we have used technique of summarizing protocol with emphasis on the techniques of qualitative content analysis. The basic idea is to unify the level of generality of presented information and increasing proportion of abstraction (Hendl, 2008).

Several techniques was applied for reduction - deletion of repetitive testimony, generalization of testimony, the construction of several specific statements into a single global, integration of certain content testimony to another global group, leaving selection key bindings allow testimony and linking content-related statements from different „locations" of interview (Hendl, 2008). During data management, we tried to use a variety of these methods. This was followed by content analysis based on the identification of key categories and subcategories and description of representative statements (see Table 1.) of the respondents (see Table 2.). Key factors and their interaction are illustrated in Figure 1.

On qualitative analysis can be viewed differently. In keeping with selected problems we prefer descriptive approach to the analysis, which is based on the premise that the process of rationalization, classification and description are themselves the analytical procedure and deeper analysis outside of these processes is highly speculative. The basic elements of applied strategies in the evaluation of qualitative data are thematic analysis and the search for links between phenomena.

Table 1. Data management, analysis and interpretation of data

\begin{tabular}{|c|c|}
\hline CATEGORY OF MEANING & THE OVERARCHING STATEMENT \\
\hline „No-experience“6 & $\begin{array}{l}\text { From the perspective of speech therapy practice is } \\
\text { incidence of these cases ,as saffron” (reduced } \\
\text { possibility of obtaining personal experience). In the } \\
\text { case of obtaining these clients the transfer of clients to } \\
\text { „more competent” experts. }\end{array}$ \\
\hline Resources of information & $\begin{array}{l}\text { The primacy of the Internet; basis even from } \\
\text { universities; specialized courses in preparation of } \\
\text { attestation; mediated experience (experienced } \\
\text { colleagues) versus ,I'm not interested.” }\end{array}$ \\
\hline $\begin{array}{l}\text { Stint knowledge about } \\
\text { symptomatic speech disorders }\end{array}$ & Basis versus practically useful level of information \\
\hline I do what I can do & $\begin{array}{l}\text { „Send the client further „, - more experienced colleagues } \\
\text { over gold. }\end{array}$ \\
\hline „No-interest" & $\begin{array}{l}\text { Are you interested in working with these clients? „Oh, } \\
\text { God, no! “ }\end{array}$ \\
\hline $\begin{array}{l}\text { Absence of specialized } \\
\text { literature }\end{array}$ & $\begin{array}{l}\text { „Due to modern trends some literature is lacking.” } \\
\text { versus „I need not solve this problem, I do not think it } \\
\text { would be in short supply." }\end{array}$ \\
\hline
\end{tabular}




\begin{tabular}{|c|c|}
\hline $\begin{array}{l}\text { Information versus fear of } \\
\text { used it }\end{array}$ & $\begin{array}{l}\text { I want information, I have it, but I'm afraid to use it in } \\
\text { practice. }\end{array}$ \\
\hline Practice is the key & Practical experience above all else. \\
\hline Delayed speech development & $\begin{array}{l}\text { Delayed speech development as a charm - without } \\
\text { practical experience but it is only a vague notion. }\end{array}$ \\
\hline Own initiative & „I am asking colleagues to experience. “ \\
\hline Specialized institutions & Absence of specialized kindergartens. \\
\hline Fear of nescience & $\begin{array}{l}\text { I do not have enough information - I cannot work with } \\
\text { clients; ,The case with which I met, It was interesting } \\
\text { for me, but I must admit that, if I worked with a similar } \\
\text { clientele, I need to have special training. I myself feel } \\
\text { that I'm not sure in the many things, and it would not } \\
\text { happen to me., }\end{array}$ \\
\hline Individualization & $\begin{array}{l}\text {,... by this time, I met with a similar case. I had myself } \\
\text { interested in the boy's visual impairment so I } \\
\text { techniques, with whom I also worked in the } \\
\text { kindergartens, the most adapted himself. , }\end{array}$ \\
\hline Team approach & $\begin{array}{l}\text { „On the other procedures we have consulted with the } \\
\text { director and the entire team in kindergarten } \\
\text {..."consultations with a wide range of experts - special } \\
\text { needs teacher, phoniatrist, ENT doctor, psychologist, } \\
\text { another speech therapist. }\end{array}$ \\
\hline Social dimension & $\begin{array}{l}\text { The biggest problem is not the primary disability and } \\
\text { associated symptomatic speech disorders, but } \\
\text { integration into the collective. }\end{array}$ \\
\hline $\begin{array}{l}\text { Orientation in available } \\
\text { resources }\end{array}$ & $\begin{array}{l}\text { Enough literature versus insufficient focus on it - „If } \\
\text { person looked for, so finds!” }\end{array}$ \\
\hline „No-necessity of” aids & $\begin{array}{l}\text { „There are already many aids that are expensive, and } \\
\text { some perhaps unnecessary.” versus ,,... it was difficult, } \\
\text { because our institution does not have many aids to work } \\
\text { with these children.”,... I tried on our own production } \\
\text { of suitable aids”; Differences between hearing and } \\
\text { visual impairment (lack of tools for clients with visual } \\
\text { impairments). }\end{array}$ \\
\hline Verbalism as reality & $\begin{array}{l}\text { „It was an experience I tried using visual aids (items, } \\
\text { toys) to the child to clarify the meaning of words.“ } \\
\text { „Every child is completely different. The biggest } \\
\text { problem I think is already being mentioned verbalisms, } \\
\text { which brings them enormous difficulties in daily life } \\
\text { and in school., }\end{array}$ \\
\hline Awareness versus experience & „I have awareness, but I have no experience.“ \\
\hline Theory versus practice & $\begin{array}{l}\text { "In theory, it is enough literature; it is difficult to find } \\
\text { publications on the methodology of work with these } \\
\text { children." }\end{array}$ \\
\hline Lifelong learning & $\begin{array}{l}\text { "Certainly some information I have, but I cannot } \\
\text { definitely say that I am an expert. When I was working } \\
\text { with such a child, I had a lot of information to study." }\end{array}$ \\
\hline Co-verbal behaviour & $\begin{array}{l}\text { "Of course, the problem is co-verbal disturbed beha- } \\
\text { viour. For some clients, it is such a serious problem that } \\
\text { can be considered as persons with reduced intellect." }\end{array}$ \\
\hline
\end{tabular}




\begin{tabular}{|l|l|}
\hline $\begin{array}{l}\text { Communicative competences } \\
\text { and their lack }\end{array}$ & $\begin{array}{l}\text { Sign language and oral communication - their } \\
\text { continuous support and development. }\end{array}$ \\
\hline $\begin{array}{l}\text { Disproportion of information } \\
\text { (visual versus hearing } \\
\text { impairment and its } \\
\text { consequences) }\end{array}$ & $\begin{array}{l}\text { "Now, yes. There was some information about children } \\
\text { with visual impairment that I had to look. In children } \\
\text { with hearing impairment, this information is more } \\
\text { known and more studied." }\end{array}$ \\
\hline $\begin{array}{l}\text { Cochlear implant as frequent } \\
\text { topic }\end{array}$ & $\begin{array}{l}\text { "Yes, this is a much debated topic both at conferences } \\
\text { and in the literature." }\end{array}$ \\
\hline $\begin{array}{l}\text { Expertise and its subjective } \\
\text { perception }\end{array}$ & $\begin{array}{l}\text { For clients with hearing impairment yes, for clients with } \\
\text { visual impairment do not. }\end{array}$ \\
\hline
\end{tabular}

Table 2. Summary data for interviews

\begin{tabular}{|c|c|}
\hline $\begin{array}{l}\text { Research sample - the number } \\
\text { of interviews }\end{array}$ & 9 \\
\hline $\begin{array}{l}\text { Structure of the sample by } \\
\text { gender }\end{array}$ & Only female $(100 \%)$ \\
\hline The average length of practice & 16,6 years \\
\hline Departmental affiliation & $\begin{array}{l}\text { - Department of MLSA (Ministry of Labour and } \\
\text { Social Affairs): } 5 \text { respondents } \\
\text { - Department ofMEYS (Ministry of Education, Youth } \\
\text { and Sports): } 4 \text { respondents }\end{array}$ \\
\hline
\end{tabular}

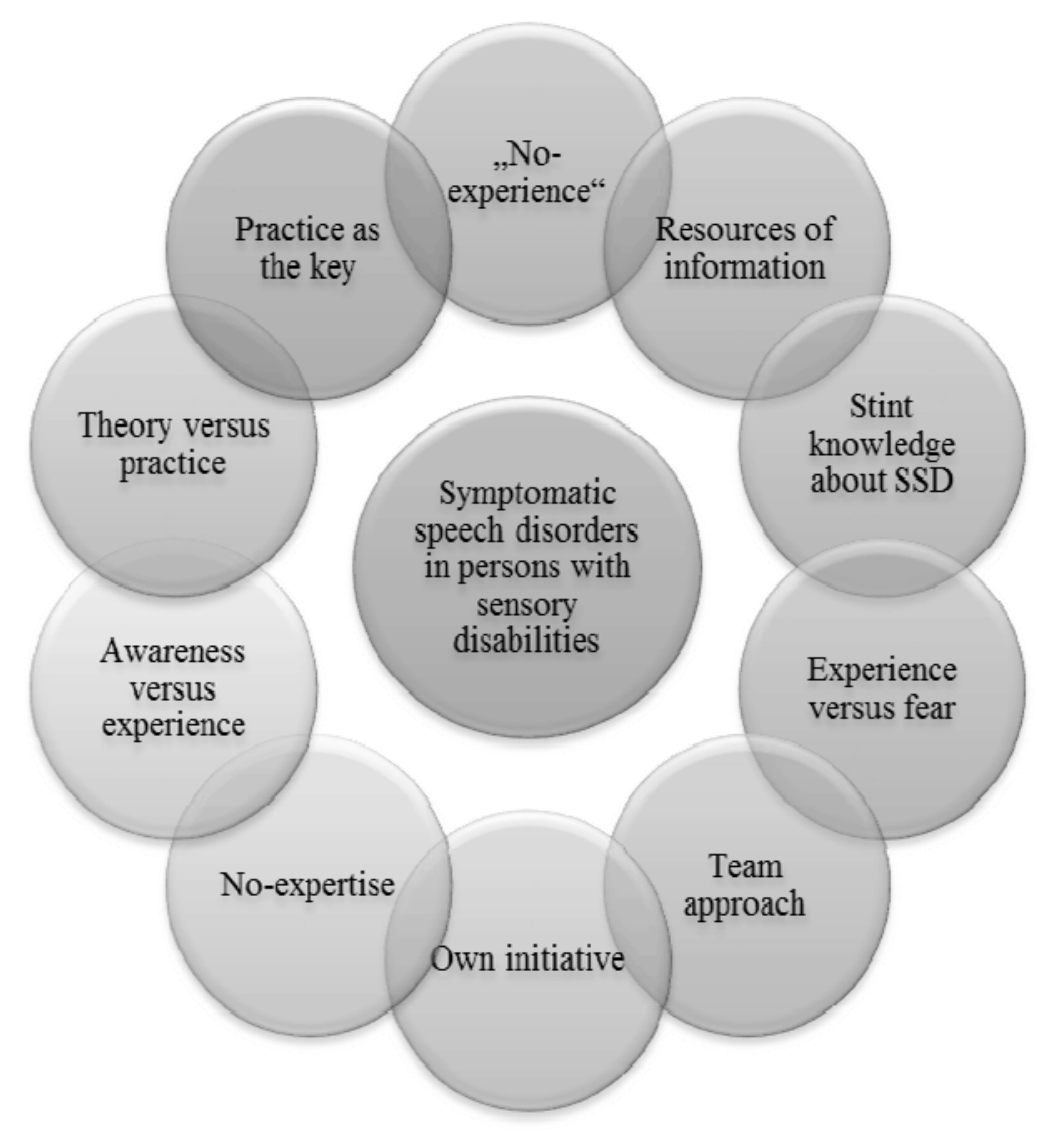

Figure 1. Determinative variables in field of symptomatic speech disorders in persons with sensory disabilities from the perspective of speech therapists 


\section{Conclusion}

Theme symptomatic speech disorders in persons with sensory disabilities currently stands at the edge of theoretical interest of experts in the field, and on the basis of our investigation, experts from speech practice, despite the fact that it may be more or less essential to the development of the individual and his communication. Speech disorder in these individuals is a dominant problem in terms of primary disability, but may significantly affect the quality of life of individuals, especially its psychosocial dimension. The nature and specific features of symptomatic speech disorders in persons with sensory disabilities were outlined in the theoretical section of the article. We wondered what attitude to this issue have speech therapists in practice, what are their experiences and needs. In-depth analysis of qualitative data showed some minor questions that provide space for deeper reflection and further applied research.

The qualitative study was designed with the following research questions:

- Which experiences have speech therapists with clients with sensory disabilities and symptomatic speech disorders?

- Do they have enough competences to work with people with sensory disabilities?

- Do they have enough information about the symptomatic speech disorders and especially information about visual and hearing impairment?

- Is work in this field characterized by interdisciplinary cooperation?

- What are for speech therapists the biggest challenges?

- What aspects of symptomatic speech disorders solve speech therapists the most?

The data show that the majority of respondents (speech therapists) already had some experience with clients with sensory disabilities. But many of them, however, admits, that they felt not enough competences for working with these people, and therefore turned instead to other professionals - client was send to their care. In this context, speech therapists also admits, that they lack sources of information in the scientific literature. However, positively looks possibility of cooperation with other experts. The majority of respondents knows on where to turn for help and with other professionals actively cooperates. But only in a few cases we can describe this cooperation as interdisciplinary. From the testimony provided by the respondents, it is clear that the biggest challenge for speech therapists are clients with visual impairment, in which the most common problem is verbalism. Speech therapists suggest that compared to persons with hearing impairment have about clients with visual impairment less information, and they don't know the specific methodology of work with these clients. Appropriate table illustrates their testimonies.

The collected data has surfaced several aspects which in our conditions determine the care of individuals with sensory disabilities from the perspective 
of speech therapists. The positions listed in the above table, illustrate the current situation and provide insight into our initial relatively unexplored area of interest. At the same time point to some key problematic issues and shortcomings. Open questions were mainly available sources and literature, the use of tools, training opportunities and more. Accentuated, however, was mainly subjective plane in terms of personal motivation, experience, sense of competence, flexibility in approaches, personal interest, lifelong learning and interdisciplinary, or transdisciplinary approach. Mutual interaction determinant indicates the above diagram. As part of that investigation, we have not sought generalizations and draw valid conclusions in general; our aim has been the primary qualitative probe into a relatively neglected area. She will then provide space for a wider analysis through quantitative design. In keeping with qualitative analysis, we sought particular description of the current status and description of key characteristics. Other aspects already outline the quantitative part of the research.

\section{Acknowledgements}

This research was carried out by the Institute of Special Education Studies, Palacký University Olomouc, with the support from the Project „Value of education description of selected factors at students with impairments I. - Education and its value as a factor in students' attitudes to training“" - (IGA_PdF_2015_013).

\section{References}

Estabrooks,W. (Ed.) (2006). Auditory-Verbal Therapy and Practice. Washington, DC: A.G. Bell.

Bergeron, J. P., Lederberg, A. R., Easterbrooks, S. R., Miller, E. M., \& Connor, C. M. (2009). Building the Alphabetic Principle in Young Children Who Are Deaf or Hard of Hearing. Volta Review, 109(2/3), 87-119.

Bruce, S. M. (2002). Impact of a communication intervention model on teachers' practice with children who are congenitally deaf-blind. Journal of Visual Impairment \& Blindness, 96, 154-168.

Chen, D. (1996). Parent-infant communication: Early intervention for very young children with visual impairment or hearing loss. Infants and Young Children, 9(2), 1-12

Daneshmandan, N., Borghei, P., Yazdany, N., Soleimani, F., \& Vameghi, R. (2009). Oral Communication Development in Severe to Profound Hearing Impaired Children After Receiving Aural Habilitation. Acta Medica Iranica, 47(5), 363-367.

Dickinson, C. M., \& Taylor, J. (2011). The effect of simulated visual impairment on speechreading ability. Ophthalmic \& Physiological Optics, 31(3), 249-257. doi:10.1111/j.1475-1313.2010.00810.x

Hendl, J. (2008). Kvalitativní výzkum: základní teorie, metody a aplikace. Praha: Portál.

Landolfi, E., Lilli, G., Marciano, E., \& Laria, C. (2011). The development of language in babies and the role of the family. Journal of Maternal-Fetal \& Neonatal Medicine, 24120-121. doi:10.3109/14767058.2011.607611

Pijnacker, J., Vervloed, M., \& Steenbergen, B. (2012). Pragmatic Abilities in Children with Congenital Visual Impairment: An Exploration of Non-literal Language and Advanced 
Theory of Mind Understanding. Journal of Autism \& Developmental Disorders, 42(11), 2440-2449. doi:10.1007/s10803-012-1500-5

Preisler, G. M. (1991). Early patterns of interaction between blind infants and their sighted mothers. Child: Care, Health and Development, 17, 65-90.

Rowland, C. (1984). Preverbal communication of blind infants and their mothers. Journal of Visual Impairment \& Blindness, 78, 297-302.

Sak-Wernicka, J. (2014). The Effect of Nonverbal Cues on the Interpretation of Utterances by People with Visual Impairments. Journal Of Visual Impairment \& Blindness, 108(2), 133-143.

Sapp, W. (2001). Maternal Perceptions of Preverbal Communication in Children With Visual Impairments. Re:View, 33(3), 133-144. 